This document is the accepted manuscript version of the following article: Di Bel1a, C., Miche1, A., Stang, H., \& Lura, P. (2017). Early age fracture properties of microstructurally-designed mortars. Cement and Concrete Composites, 75, 62-73. https://doi.org/10.1016/j.cemconcomp.2016.11.004

\title{
1 Early age fracture properties of microstructurally-designed mortars
}

2 Carmelo Di Bella ${ }^{\mathrm{a}, \mathrm{b}, 1}$, Alexander Michel ${ }^{\mathrm{c}}$, Henrik Stang ${ }^{\mathrm{c}}$, Pietro Lura ${ }^{\mathrm{a}, \mathrm{b}}$

3

Empa, Swiss Federal Laboratories for Materials Science and Technology, Dübendorf,

5 Switzerland

${ }^{\mathrm{b}}$ ETH Zurich, Swiss Federal Institute of Technology Zurich, Switzerland

${ }^{c}$ Technical University of Denmark, Department of Civil Engineering, Kgs. Lyngby, Denmark

Keywords: fracture properties; early-age cracking; compact tension test; inverse analysis; mortar

\section{Introduction}

Transportation agencies strive to minimize the risk of cracks in structural concrete, as damaged structures accelerate deterioration resulting in increased maintenance costs and reduced service life $[1,2]$. Cement-based materials are particularly susceptible to cracking at early-ages, when the

\footnotetext{
${ }^{1}$ Corresponding author: Carmelo Di Bella, carmelo.dibella@empa.ch
} 
material properties are still developing and the rate of shrinkage and thermal deformations is high $[3,4]$. A precise knowledge of the mechanical properties, and in particular of the fracture properties, is at the basis of virtually every approach for modeling crack initiation and propagation. Indeed, advanced modelling approaches taking into account the formation of cracks as well as their propagation necessarily require several time-dependent material properties to be known, such as e.g., tensile strength, elastic modulus, Poisson's ratio, and volumetric deformations as well as fracture properties $[5,6]$.

While most of the aforementioned properties can be more or less easily measured as a function of time, the determination of the early-age volumetric deformations such as drying shrinkage, creep, and/or relaxation at a given hydration degree is more complicated [7]. Indeed, at early-age the microstructure of cement-based materials is continuously evolving due to hydration, which may interfere with an accurate determination of such long-term properties [7]. Further, even in the case in which the testing time required to measure material properties, such as e.g. the elastic modulus or the tensile strength, is short enough to neglect microstructural changes due to hydration, additional limitations may be encountered at early-age. For example, the assessment of the dependency of material properties on the moisture content or changes in temperature at earlyage is challenging. In fact, the introduction or the withdrawal of water as well as a change in temperature at early-age may result in a change in the microstructure evolution.

Recently, a technique based on the replacement of unreacted binder by quartz to produce equivalent systems at given hydration stages has been presented [8]. Starting from the knowledge of the volume fractions of unreacted binder as a function of time, a new mixture is prepared in which the amount of unreacted binder is replaced with an equal volume of non-reactive quartz filler [8]. The new mixture (or equivalent mixture) has exactly the same porosity and the same volume fraction of the hydration products and reproduces the microstructure of the original mixture at a given hydration stage [8]. Once all the remaining binder has completely reacted, the equivalent mixture represents a static system, whose microstructure does not change over time and/or testing [8]. In the equivalent systems, the binder is assumed to have completely reacted after 3 months of curing in moist conditions [7]. The volume fractions of unreacted binder to be replaced as a function of time are determined from the real mixture, for example through quantitate X-ray diffraction using Rietveld analysis. In this study, five hydration stages are investigated, corresponding to five hydration ages (namely 1, 3, 7, 28, and 91 days). At those ages, the volume fraction of the unreacted cement was calculated from the real mixtures. More 
details regarding the determination of the volume fractions can be found in [8]. Afterwards, five corresponding new equivalent mixtures were prepared.

A comprehensive and systematic comparison between the real systems and the equivalent systems has been recently published [7]. This study, including both mechanical properties (compressive strength, flexural strength and elastic modulus) as well as degree of hydration and calcium hydroxide content by thermogravimetric analysis (TGA) and pore structure by mercury intrusion porosimetry (MIP), supported the validity of the equivalent systems approach [7]. In the present paper, the validation of the approach is extended to the fracture properties.

While the most straightforward method to determine the fracture properties of cement-based materials is represented by the direct tension test, it bears several disadvantages. For example, the direct tension test is more sensitive to eccentricities, rotational boundary conditions, and possibility of multiple cracking formations [5, 9]. Hence, more often, the materials properties are estimated by indirect test methods such as the three-point bending test, the wedge-splitting test or the compact tension test (CTT) [10-12].

In this paper, the material properties prior to cracking and the fracture properties of one real (at five stages of hydration) and five respective equivalent mortar mixtures were obtained by inverse analysis of load-displacement curves obtained from the CTT. Specifically, the material properties were obtained by inverse analysis based on the hinge model $[10,13]$. The results obtained by the inverse analysis were afterwards verified by means of FEM simulations using the commercial finite element package TNO DIANA. For further validation of crack initiation and propagation, digital image correlation techniques were applied on a sequence of pictures acquired during testing. This non-destructive approach based on the comparison of consecutive digitized images taken during deformation allows for the derivation of the full-field surface displacement and strains of objects under load $[14,15]$. Finally, the material properties deduced by means of inverse analysis i.e., elastic modulus, tensile strength, and fracture energy of the real and equivalent mortar mixtures, were compared and their difference statistically evaluated through the analysis of variance (ANOVA) [16] to validate the equivalent-systems technique. Additionally, differences between the equivalent and real systems regarding the peak points on the load-displacement points (peak force and crack mouth opening) were statistically evaluated using multivariate ANOVA (MANOVA).

Afterwards, the equivalent approach is employed for the first time to investigate the effect of the moisture content on the elastic modulus, tensile strength, and fracture energy at early-age. 
94

\section{Materials, mix proportions and curing}

One real and five equivalent mortar mixtures were compared in this study. The real mortar mixture was prepared using an ordinary Portland cement (OPC) CEM I 52.5N with a density of $3.13 \mathrm{~g} / \mathrm{cm}^{3}$. The following mineralogical composition (by mass) was measured by quantitative Xray diffraction: $61.2 \% \mathrm{C}_{3} \mathrm{~S}, 16.2 \% \mathrm{C}_{2} \mathrm{~S}, 6.6 \% \mathrm{C}_{3} \mathrm{~A}, 10.5 \% \mathrm{C}_{4} \mathrm{AF}$ and $1.8 \% \mathrm{CaSO}_{4}$. The oxide composition of the OPC is shown in Table 1.

The sand used to prepare the mortar mixtures had a density of $2.65 \mathrm{~g} / \mathrm{cm}^{3}$, average grain size D50 of $312 \mu \mathrm{m}$, maximum size of $650 \mu \mathrm{m}$, and water absorption of $0.2 \%$. The water-to-solid ratio used was equal to 1.6 by volume (ranging from 0.56 to 0.51 by mass according to the age investigated), while the amount of sand corresponded to $50 \%$ of the total mortar volume. It should be noted that the word solid here refers to the sum of the cement and the quartz, the latter used in place of the unreacted cement. Due to the difference in density between cement and quartz the w/s was calculated in volume base.

Five equivalent mortar mixtures were prepared to mimic five different hydration ages of the real mortar mixture, namely $1,3,7,28$, and 91 days. In the equivalent mortar mixtures, different volume fractions of the OPC were replaced by quartz (replacement calculated on volume base) with a density of $2.65 \mathrm{~g} / \mathrm{cm}^{3}$ and a particle size distribution comparable to that of the cement [7]. The water-to-solid ratio and sand volume were kept constant at each equivalent age and were identical to those of the real mortar mixture. The cement and sand used to prepare the equivalent mortar mixtures are the same as for the real mortar system. The mixture proportions (by volume) of the real and equivalent mortars are shown in Table 2.

Both real and equivalent mortars were mixed in a Hobart mixer in accordance with NF EN 196-1 [17]. The cement and the quartz filler (the latter used only in the equivalent mortars) were mixed for $30 \mathrm{~s}$ at low speed with water in the mixing bowl. While still mixing at low speed, the sand was added to the mixing bowl within $30 \mathrm{~s}$, followed by $30 \mathrm{~s}$ of mixing at higher speed. After $90 \mathrm{~s}$ rest, the mortar was again mixed for final $60 \mathrm{~s}$ at high speed. The mortar was cast into a customized formwork $\left(125 \times 150 \times 10 \mathrm{~mm}^{3}\right)$ equipped with two insertions to accommodate the two rods for the tensile load transmission during testing (Figure 1).

After 24 hours the samples were demolded. The equivalent mortar samples were wrapped in wet towels and sealed in plastic bags for at least three months of curing in an environmental chamber at $20{ }^{\circ} \mathrm{C}$ and $100 \% \mathrm{RH}$. Similar to the equivalent mortar samples, real mortar samples were 
wrapped in wet towels and sealed in plastic bags, except for the $1 \mathrm{~d}$ sample that was directly tested after demolding. The remaining samples were cured in an environmental chamber at $20{ }^{\circ} \mathrm{C}$ and $100 \%$ RH until testing at 3, 7, 28, or 91 days of age.

At each testing age, three mortar samples were tested both for the equivalent and the real systems. It should be noted that the real specimens were tested at the indicated curing age, while the equivalent specimens were tested after 3 months of curing. Three months correspond to the minimum time needed to simulate the hydration age of the real systems.

Table 1. Chemical composition of CEM I $52.5 \mathrm{~N}$ [mass \%].

\begin{tabular}{llllllllll}
\hline $\mathrm{SiO}_{\mathbf{2}} \%$ & $\mathrm{Al}_{2} \mathrm{O}_{\mathbf{3}} \%$ & $\mathrm{Fe}_{2} \mathrm{O}_{\mathbf{3}} \%$ & $\mathrm{CaO} \%$ & $\mathrm{MgO} \%$ & $\mathrm{~K}_{\mathbf{2}} \mathrm{O} \%$ & $\mathrm{Na}_{\mathbf{2}} \mathrm{O} \%$ & $\mathbf{S O}_{\mathbf{3}} \%$ & $\mathrm{TiO}_{\mathbf{2}} \%$ & $\mathbf{P}_{\mathbf{2}} \mathrm{O}_{\mathbf{5}} \%$ \\
\hline 20.10 & 5.02 & 3.14 & 64.48 & 0.99 & 0.87 & 0.17 & 3.33 & 0.23 & 0.33 \\
\hline
\end{tabular}

Table 2. Mixture proportions of the real and the five equivalent mortars $\left[\mathrm{kg} / \mathrm{m}^{3}\right]$.

\begin{tabular}{lcccccc}
\hline & Real & Equivalent 1d & Equivalent 3d & Equivalent 7d & Equivalent 28d & Equivalent 91d \\
\hline Cement & 599 & 245 & 357 & 428 & 496 & 528 \\
Quartz & 0 & 301 & 206 & 145 & 88 & 60 \\
Sand & 1331 & 1331 & 1331 & 1331 & 1331 & 1331 \\
Water & 306 & 306 & 306 & 306 & 306 & 306 \\
\hline
\end{tabular}

\section{Experimental and analytical procedure}

During the compact tension test, an eccentric tensile load (at constant displacement rate of $0.12 \mathrm{~mm} / \mathrm{min}$ ) was applied by means of two rods with a diameter of $20 \mathrm{~mm}$ to promote initiation and propagation of a single crack at the tip of the notch. The notch was introduced into the sample by water-cooled saw cutting to induce local stress concentrations and create the conditions for the initiation and propagation of a single crack. The notch thickness and length was $0.5 \mathrm{~mm}$ and $60 \mathrm{~mm}$, respectively. The geometry of the sample is shown in Figure 1. The sample's thickness was $10 \mathrm{~mm}$ which promotes plane stress conditions [14], while also reducing the time to reach mass equilibrium to investigate the effect of the moisture content (see section 4.6). The crack mouth opening displacement (CMOD) was measured using a clip gage that was placed on the notched surface of the sample. 
150

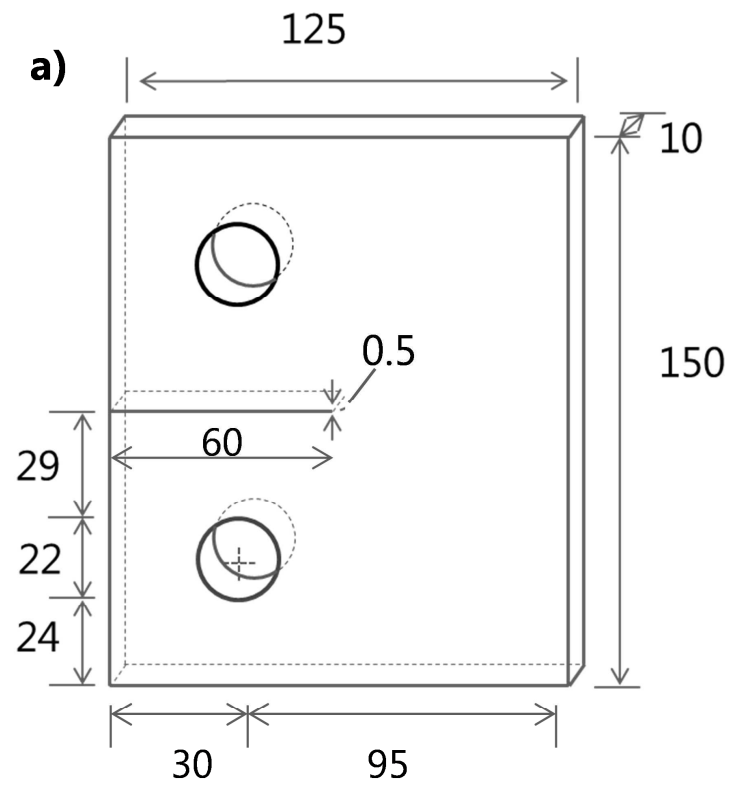

b)

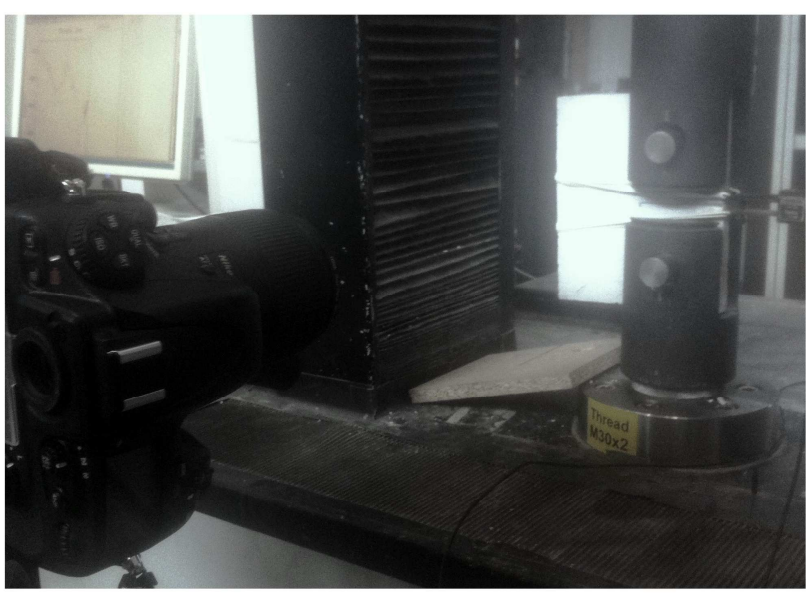

Figure 1. a) Specimen's geometry used for the CTT, the dimensions indicated are in (mm); b) setup for the CTT testing including the camera for DIC.

The experimentally-determined load-displacement curves from the CTT were employed to obtain the fracture material properties through inverse analysis based on the cracked hinge model (CHM). Ulfkjaer et al. [18] (with further improvements by Olesen [19]) presented a semianalytical method for describing the fracture propagation for Mode-I, i.e., the cracked hinge model. The main advantage of the CHM consists in the fact that it yields analytical solutions for the entire load-crack opening curve. Later, Østergaard [10] proposed an inverse analysis algorithm based on the CHM to retrieve information from the wedge splitting test. However, in the CHM the derivation of an analytical solution including multi-linear softening material behavior remained troublesome. Skoček and Stang [13] extended the inverse analysis for wedge splitting tests based on the CHM including multi-linear softening behavior with the intent to increase the accuracy of test simulations. In the present study, inverse analyses including multilinear softening behavior developed in [13] is employed to simulate the CTT results and to calculate the elastic modulus, tensile strength, and fracture energy. Figure 2 shows the implementation of the CHM, developed in [18] and [19], to the wedge splitting test geometry. The CHM simulates the area directly surrounding the propagating crack using the loading and deformation shown in Figure 2(b) and the stress distribution in Figure 2(c). The rigid boundaries 
170

171

172

for $i<N$ and

$$
g(w)=b_{i}-a_{i} w \quad \text { with } \quad w_{(i-1)}<w<w_{i}
$$

where $w_{i}$ corresponds to the intersection of $i$-th and $i+1$-th line and has the form

$$
w_{i}=\frac{b_{i}-b_{i+1}}{a_{i}-a_{i+1}}
$$

$$
w_{N}=w_{c}=\frac{b_{N}}{a_{N}}
$$

181 with $N$ equal to the number of lines in the softening curve.

182 The inverse analysis to determine the tensile strength, Young's modulus, and cohesive relation

183 consists then of three steps that are repeated until convergence is reached. In the first step the

184 Young's modulus is determined from the experimental data corresponding to the elastic loading.

185 Once the Young's modulus is found, the tensile strength and the first descending branch of the 186 softening curve $a_{1}$ are computed. Finally, $\mathrm{N}-1$ computations are preformed to find $a_{i}$ and $b_{i}$, with $187 i=2 \ldots N$ defining the multi-linear softening behavior. A sketch of the multi-linear softening 188 curve is shown in Figure 2(d). Additional details on the CHM and the inverse analysis approach 189 are available in the literature, see e.g. [10], [13], [18], and [19]. 


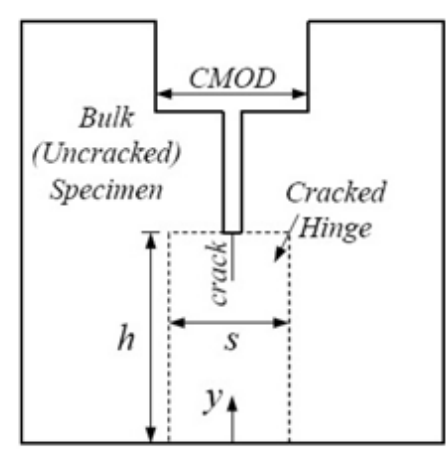

(a)

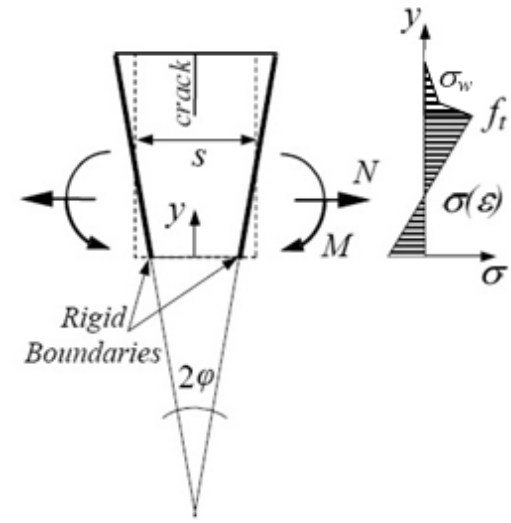

(b)

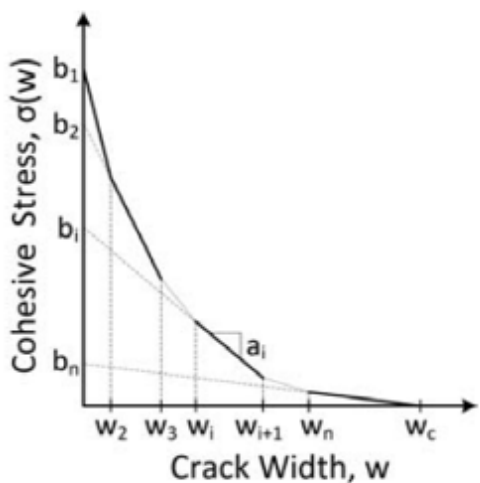

(d)

Figure 2. (a) The wedge split test specimen with the cracked hinge model applied (after [10]), (b) loading and deformation of the hinge (after [19]), (c) the assumed stress distribution (after [19]), and (d) sketch of the multi-linear softening curve (after [20]).

In addition to the clip gage measurements, digital images were repeatedly captured at $10 \mathrm{~s}$ intervals using a Nikon D800 36.3 megapixel $(7360 \times 4912$ pixels $)$ camera body with a $60 \mathrm{~mm}$ focal length macro lens (AF-S Micro Nikkor $60 \mathrm{~mm}$ f/2.8G ED). Prior to loading of the test specimens, three images were captured of the specimen surface and a fourth image including a scale. The lens was placed approximately $1000 \mathrm{~mm}$ from the specimen surface, resulting in images covering a region of application of approximately $65 \times 65 \mathrm{~mm}^{2}$, with each pixel representing $11.7 \times 11.7 \mu \mathrm{m}^{2}$ of physical space. A LED ring flash was affixed directly to the lens to evenly light the specimen surface.

Captured images were subsequently processed with a commercially-available software package [21], which utilized a stochastic speckle pattern to identify unique regions, called facets, on the specimen surface at each measurement time. The stochastic speckle pattern on the specimen surface was created prior to testing using black and white spray paint. The facet size within the commercially available software package was set to $15 \times 15$ pixels $\left(175 \times 175 \mu \mathrm{m}^{2}\right)$. The software tracked movements of the facets and utilized standard DIC techniques to compute deformations of the specimen surface. Additional information on the hardware used and the DIC technique is available in [15, 21-23].

Finally, a statistical evaluation of the differences between the real and equivalent material properties investigated in this study, i.e., elastic modulus, tensile strength, and fracture energy was performed by means of ANOVA. Specifically, a two-way analysis of variance was applied 
taking into account two fixed factors; the five hydration ages and the two systems (real and equivalent). The null hypothesis of no significant difference was tested by comparing the p-value to the significance level $\alpha$ (assuming $\alpha=0.05$ ). Similarly, MANOVA using the Pillai test [24] was performed for the peak points on the load-displacement curves experimentally obtained by CTT.

\section{Results and discussion}

\subsection{Load-displacement curve}

In Figure 3, the load-displacement curves obtained for the equivalent and real mortars are compared. For ease of illustration, the various testing ages are presented in two graphs. In Figure 3a, the equivalent ages of 1, 7 and 91 days are shown; while in Figure $3 \mathrm{~b}$ the remaining results for the equivalent ages of 3 and 28 days are presented. The curves shown represent the average behavior of three repetitions of each test. It should be noted that the term equivalent refers to the equivalent mortars which were cured for a minimum of 91 days before being tested and reproducing a given hydration age. On the other hand, the real mortars were tested at the actual age indicated.

In general, the load-displacement curves as a function of the hydration age for all specimens tested show a similar shape, which is typical for quasi-brittle materials, i.e. they exhibit moderate strain hardening prior the attainment of the peak load, followed by rapid strain softening [25]. Nevertheless, the area below the curve increases as the hydration age increases. Similarly, the peak load is a function of the age: the highest peak load is obtained for $91 \mathrm{~d}$ old mortars (ranging between 310 and $340 \mathrm{~N}$ ) while the lowest peak load was measured on the $1 \mathrm{~d}$ old specimens (approximately $140 \mathrm{~N}$ ).

In general, it can be observed from the presented results that the equivalent mortar specimens follow the load-displacement behavior exhibited by the real mortars as a function of time. Excellent agreement between the measured load-displacement curves are observed for mortars at 1 and 7 days. For the remaining test specimens, it should be noted that the equivalent mortars systematically show a reduced peak load. Such difference may be due to an underestimation of the degree of hydration in the real mortars, which will result in a higher replacement of cement binder with quartz in the equivalent mortars [7]. While on one hand the evaluation of the degree of hydration could be improved by increasing the number of samples measured or combining different techniques, it should be noticed that some inherent limitations may arise by the test 
a)

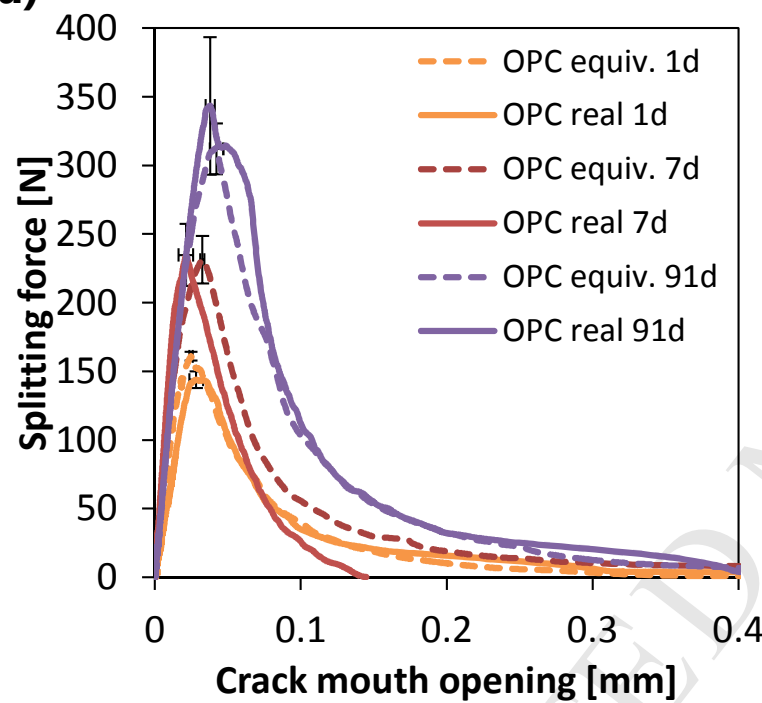

b)

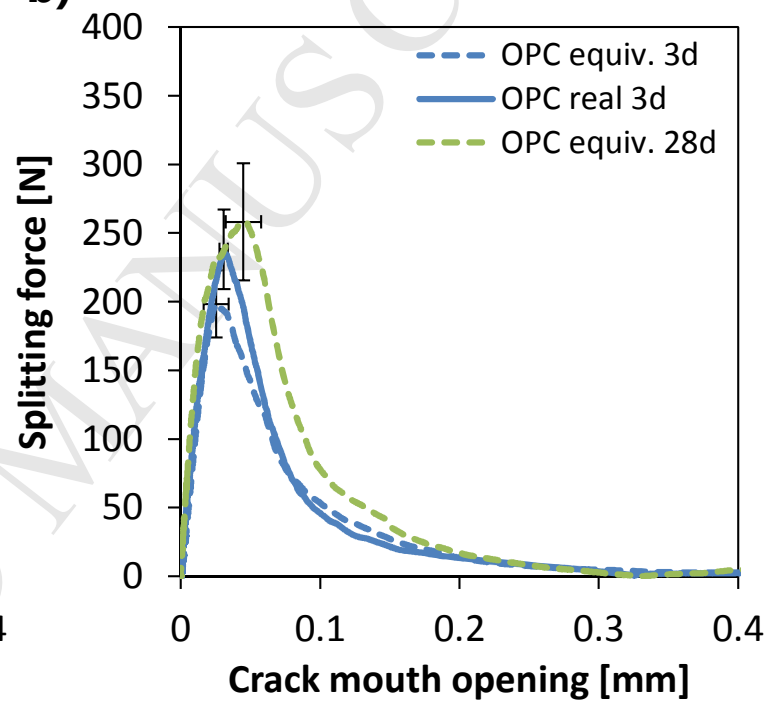

255

methods itself or the sample preparation (for example when stopping the hydration by isopropanol). Nevertheless, it should be emphasized that predicting a precise hydration age was not the goal of the equivalent systems, but having a microstructure that enables the investigation of time dependent and moisture dependent properties without changing in time or during testing.

It should be also emphasized that the slight deviation seen in the real specimen at 91 days at the beginning of the post-peak phase can be due to the testing method such as a shift of the clip gage.

Figure 3. Load-displacement curves comparison measured on the real and equivalent mortars at different hydration ages: a) $1 \mathrm{~d}, 7 \mathrm{~d}$, and $91 \mathrm{~d}$; b) $3 \mathrm{~d}$ and $28 \mathrm{~d}$. The error bars represent the standard deviation calculated at the load peaks and the displacement measured on the different repetitions for each age.

Moreover, it should be noted that discrepancies between the real and equivalent mortars as seen in Figure 3 also arise from the reproducibility related to the CTT method itself. To illustrate this point, Figure 4 shows the load-displacement curves of all tested specimens for one real and one equivalent age, i.e. 3 days. To analyze this issue, the peak points of the curves (i.e., simultaneously the peak forces and the crack mount opening corresponding to the peak forces) were compared between the real and equivalent systems using two-way MANOVA (with age and type of system as crossed factors). No statistically significant differences (at significance level of 
0.05) were found in this case between real and equivalent systems (the P-value according to the Pillai test was 0.66), whereas the specimen age was found to be a significant factor (P-value below 0.01).

271 The actual differences between the real and the equivalent mortars will be discussed more in 272 detail with regard to the materials properties investigated (elastic modulus, tensile strength, and 273 fracture energy) by means of ANOVA in the following section.
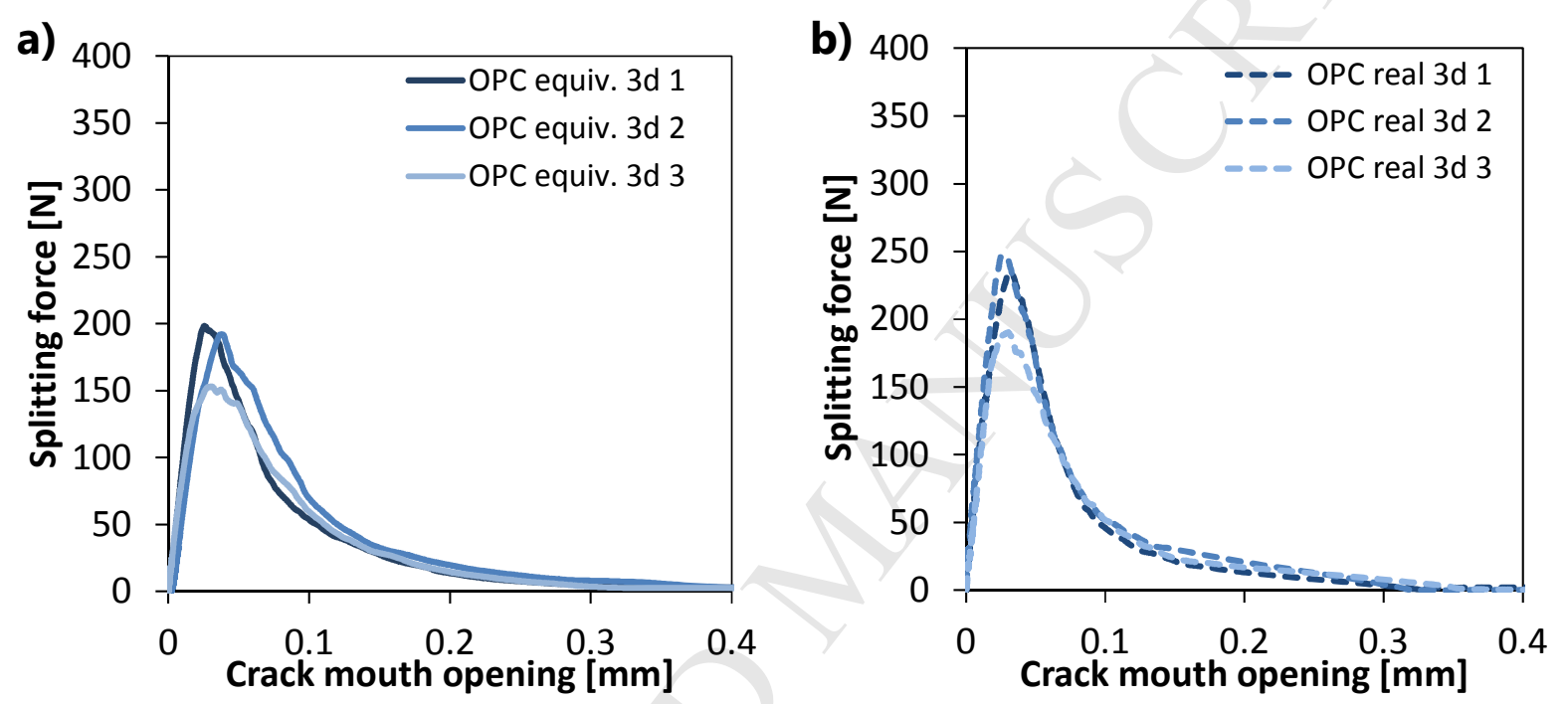

Figure 4. Load-displacement curves obtained from duplicate samples: a) 3 d equivalent mortar

\subsection{Inverse Analysis}

280 Results of the inverse analysis are shown in Figure 5, in which experimental and modelled load-

281 displacement curves are compared to each other. For the sake of brevity, only results of 282 equivalent mortars at the equivalent age of 3 and 91 days are shown, including three repetitions 283 for each equivalent age. As can be seen from the presented results, excellent agreement between 284 load-displacement curves determined by inverse analysis and experimentally determined load285 displacement curves is obtained. For example the three experimental load-displacement curves at 91 days directly overlap with the simulated ones. 

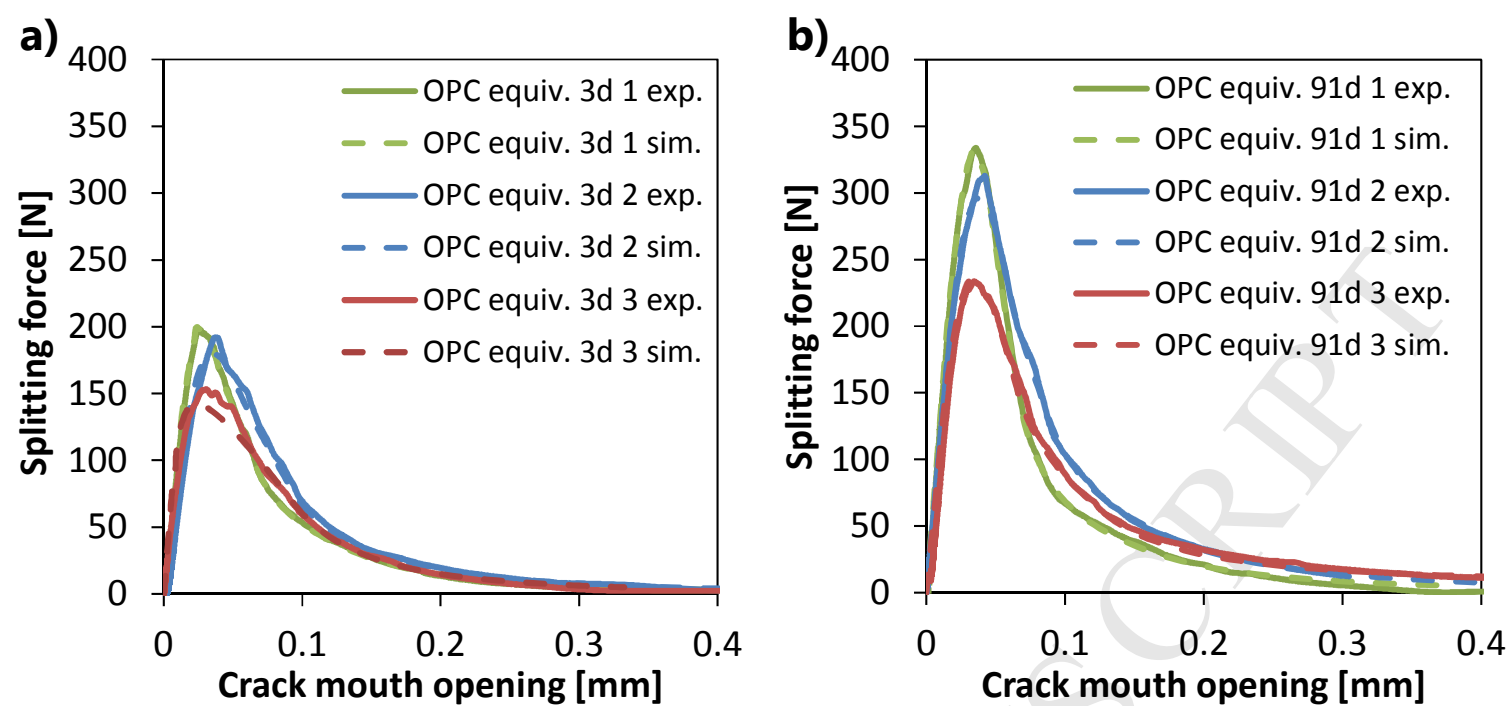

Figure 5. Comparison of the measured and the computed load-displacement curves for the a) $3 \mathrm{~d}$ equivalent mortars and b) $91 \mathrm{~d}$ equivalent mortar samples.

Figure 6 (a through c) shows the comparison of the material properties between the equivalent and the real mortars in terms of the elastic modulus, tensile strength, and fracture energy obtained by inverse analysis. Error bars represent the standard deviation.

As evident from Figure 6, the elastic modulus and the tensile strength increase with age and reduction of porosity, as expected. Similarly, the fracture energy increases with time due to the increase in number of bonds forming in the mortar as cement hydration proceeds $[12,26]$.

Comparable results in terms of elastic modulus and fracture energy were found for the real and the equivalent mortars (Figures 6a and 6c). Most of the determined values fall within one standard deviation of the mean except for the results of the mortar specimens with an equivalent age of $7 \mathrm{~d}$, for which the results clearly diverged. It should be noted that only two repetitions were available with regard to the $7 \mathrm{~d}$ real mortar, as one sample broke during demolding. While at $7 \mathrm{~d}$ the tensile strength results obtained by inverse analysis for the real and the equivalent mortars are similar, erroneous values were returned by the inverse analysis in terms of elastic modulus and more obviously in terms of fracture energy. This is also shown by the experimental load-displacement curve (in Figure 3a), where the OPC real $7 \mathrm{~d}$ curve rapidly approaches zero already at a crack mouth opening of approximately $0.14 \mathrm{~mm}$, hence resulting in a reduced fracture energy. Further, the initial slope is much steeper compared to the other results. No data are available for the real mortar at 28 days as all samples inadvertently broke during handling. 
The tensile strengths of the real and the equivalent mortars are also comparable, ranging approximately from 1 to $2.5 \mathrm{MPa}$ for the equivalent ages investigated in this study.

The two-way analysis of variance on the test results obtained by inverse analysis taking into account the whole evolution of the elastic modulus, tensile strength and fracture energy showed that no statistically significant differences (at significance level of 0.05) exist between the real and the equivalent mortars, hence supporting the validity of the equivalent method approach. The P-values for the considered factor (real or equivalent system) were: $0.15,0.26,0.12$, for the fracture energy, tensile strength and E-modulus, respectively.

a)

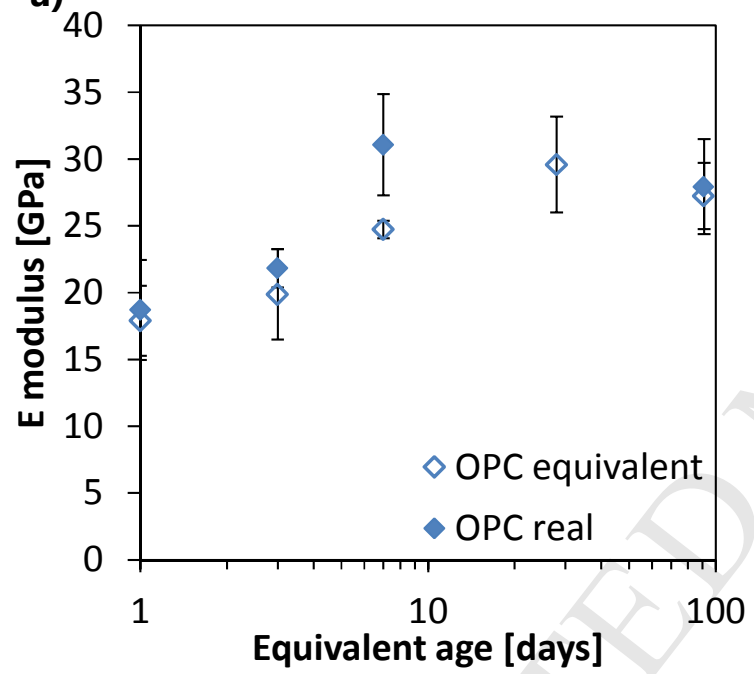

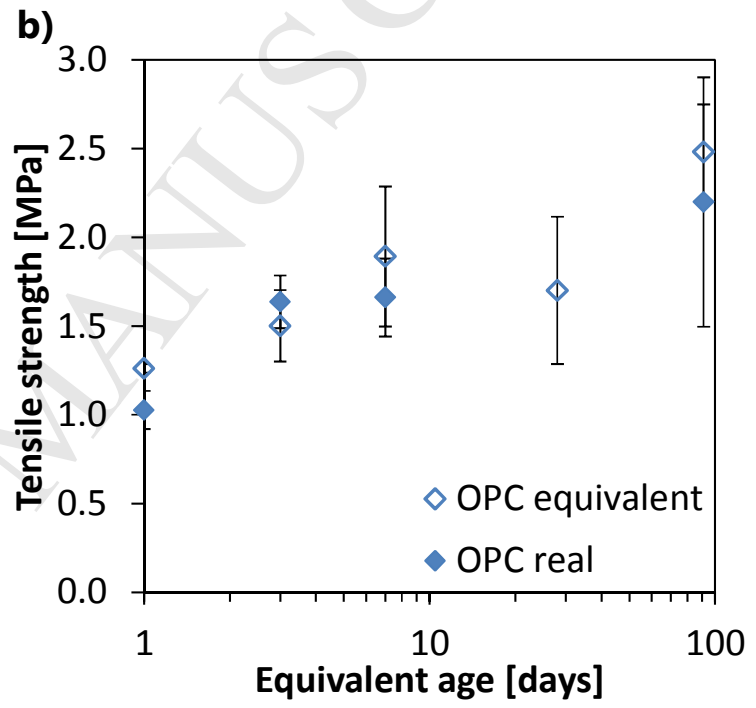

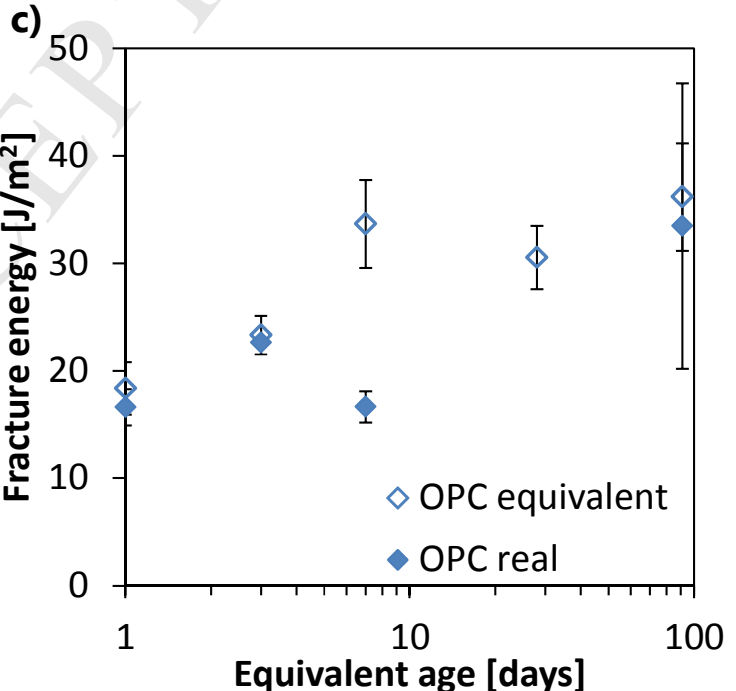

Figure 6. Comparison of the real and equivalent mortars: a) elastic modulus, b) tensile strength, and c) fracture energy as a function of the equivalent age. 
As to further validate the elastic modulus results obtained by the inverse analysis, in Figure 7 the elastic moduli evolution as a function of the equivalent age obtained by inverse analysis are compared to the statically and dynamically determined elastic modulus measurements on companion specimens, as presented in [7]. The static and dynamic elastic moduli were measured on $40 \times 40 \times 160 \mathrm{~mm}^{3}$ mortar prisms (see [7] and [27] for details on the experimental methods). The elastic moduli of the real and equivalent mortars obtained by inverse analysis of the CTT results are closer to the corresponding statically-determined elastic moduli, this is expected considering the similar time spans of both tests. An exception is the real mortar with an equivalent age of 7 days, for which the elastic modulus falls in between the experimentallymeasured dynamic and static elastic modulus. For the equivalent mortars (Figure 7b), excellent agreement between the statically-determined elastic moduli and elastic moduli determined by means of the inverse analysis is found for the equivalent ages of 1, 7, and $91 \mathrm{~d}$. For equivalent ages of 3 and $28 \mathrm{~d}$, the results are still within one standard deviation of the mean elastic modulus.
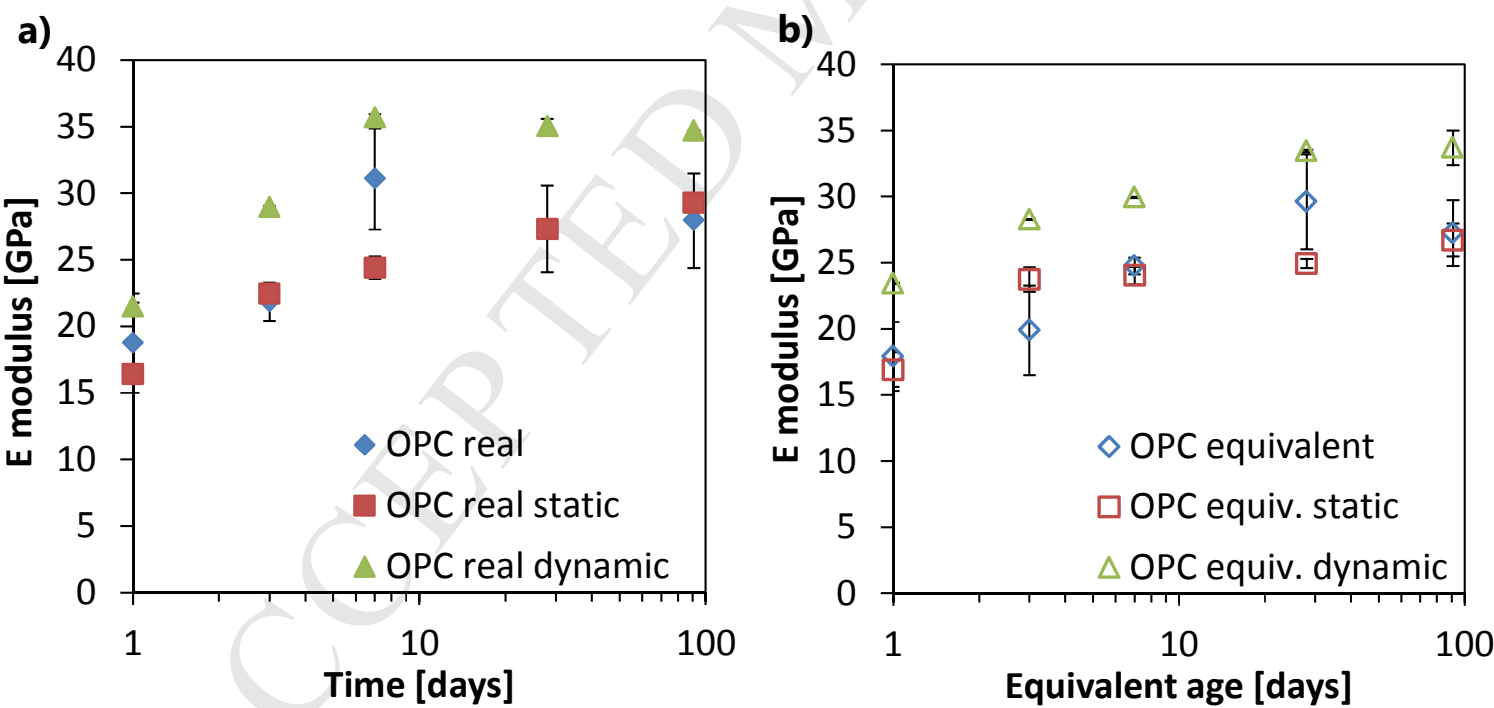

Figure 7. Comparison of the elastic modulus results obtained by inverse analysis and measured on companion specimens by means of static and dynamic techniques.

\subsection{FEM Simulation of the CTT load-displacement curve}

To further validate the data obtained by inverse analysis, the tensile response of the CTT was modeled using the commercial finite element package TNO DIANA. The CTT was simulated by 

0 71 73 74

means of a 2D model assuming plane stress conditions and consisted of 9550 three-node triangular isoparametric plane stress elements with 4932 nodes representing the concrete, steel, and crack domains (see Figure 8a). Fillets were used at the tip of the notch to reduce artificial stress intensities in this region (see Figure $8 b$ ). The crack path was predefined and modelled by means of zero-thickness two-node interface elements assuming Mode-I fracture. Tension softening of the material was described based on a cohesive discrete cracking model in which multi-linear softening relations are adopted from [10]. A nonlinear solution of the system of equations was obtained using a standard Newton-Raphson method with a displacementcontrolled convergence criterion.

To investigate the impact of varying mesh sizes on the solution of the problem, a range of interface discretization were studied for the $91 \mathrm{~d}$ equivalent mortar system. The number of zerothickness interface elements along the predefined crack path (see Figure 8) was varied between 10 and 100 elements. The input parameters determined by inverse analysis of CTT results are presented in Table 3. For the investigation of the effect of varying mesh sizes on the solution, the results of the surface crack width predicted by the FEM model for the various mesh sizes were normalized to the results obtained with 100 elements discretizing the predefined crack path. Results of the mesh analysis, given in Figure 9, indicate that the influence of the crack interface discretization was negligible $(<0.1 \%$ difference between the different mesh sizes) for more than 20 crack interface elements. Accordingly, the crack interface was discretized with 100 elements for all solutions.

The input data, i.e., elastic modulus, tensile strength, and cohesive relations, were obtained from the inverse analysis of experimentally determined load-displacement curves at the different hydration ages; see Section 4.1 - Load-displacement curve. While the Poisson's ratio $v$ was assumed to be 0.2 , it has no influence on the results, due to the geometry that is close to plane stress conditions. An overview of the input parameters for all simulations is provided in Table 3. 72 
Table 3. Input parameters for FEM simulations.

\begin{tabular}{|c|c|c|c|c|c|c|c|c|c|c|}
\hline & & $E$ & $f_{t}$ & $a_{1}$ & $b_{1}$ & $a_{2}$ & $b_{2}$ & $a_{3}$ & $b_{3}$ & $N_{s t}$ \\
\hline \multirow{5}{*}{$\begin{array}{l}\text { Equivalent } \\
\text { system }\end{array}$} & $1 \mathrm{~d}$ & 17.89 & 1.26 & 57.85 & 1 & 13.23 & 0.50 & 1.64 & 0.13 & $\begin{array}{c}40 \\
\text { steps }\end{array}$ \\
\hline & $3 d$ & 19.87 & 1.50 & 51.58 & 1 & 22.06 & 0.75 & 1.96 & 0.14 & $\begin{array}{c}2.5 \mathrm{E}-4 \\
\mathrm{~mm}\end{array}$ \\
\hline & $7 \mathrm{~d}$ & 24.73 & 1.89 & 47.82 & 1 & 15.13 & 0.46 & 0.54 & 0.06 & $\begin{array}{l}+ \\
70\end{array}$ \\
\hline & $28 \mathrm{~d}$ & 29.59 & 1.70 & 35.48 & 1 & 7.25 & 0.37 & 2.32 & 0.17 & $\begin{array}{c}\text { steps } \\
1.0 \mathrm{E}-2\end{array}$ \\
\hline & $91 \mathrm{~d}$ & 27.22 & 2.48 & 46.15 & 1 & 23.66 & 0.70 & 1.38 & 0.11 & $\mathrm{~mm}$ \\
\hline
\end{tabular}

Abbreviations: $E$ - Young's modulus (GPa), $f_{t}$ - tensile strength (MPa), $a_{i}$ and $b_{i}$ - parameters defining multi-linear softening curve (see also Section 3 ), and $N_{s t}$ - applied displacement scenario in FEM model

In Figure 10, the experimentally-determined load-displacement curves of the equivalent mortars at different equivalent ages are compared to the results from the finite-element calculations. As can be seen from the presented results, numerically determined load-displacements curves are in excellent agreement with the experimental data for all equivalent ages except $28 \mathrm{~d}$, which confirms the validity of the inverse analysis results. The difference observed at 28 days could be due to the fact that the crack was not really straight rising from a mixed-mode behavior, or that the crack did not initiate at the notch, or branched. Results of the digital image correlation for the equivalent mortar at 28 days, see Figure 11, clearly indicates a 'bending' of the crack, i.e. the crack does not follow the predefined crack path in the FEM model, which may explain the differences observed between the experimental data and FEM predictions. 
a)

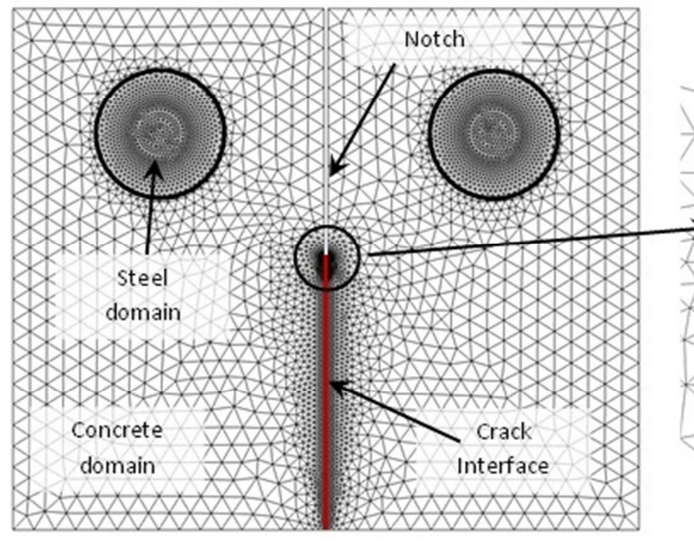

b)

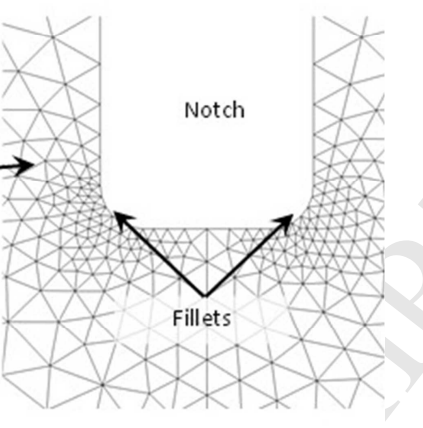

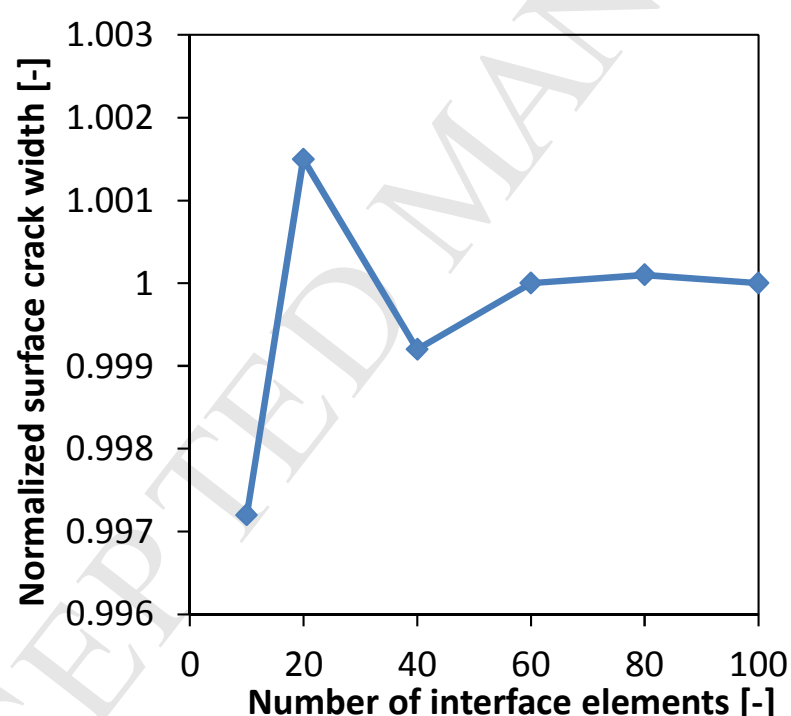

Figure 9. Normalized surface crack width as a function of the number of interface elements. 
400

401

402

403

404

405 Figure 11. Digital image correlation results for the equivalent mortar at 28 days: crack 406 propagation.

407

408

409

410

411

412

Figure 10. Comparison of the measured and the simulated load-displacement curves for the a) $1 \mathrm{~d}, 7 \mathrm{~d}$, and $91 \mathrm{~d}$ equivalent mortars and b) $3 \mathrm{~d}$ and $28 \mathrm{~d}$ equivalent mortar samples.

\subsection{Digital Image correlation}

A sequence of pictures was taken during the CTT at intervals of $10 \mathrm{~s}$. Digital image correlation techniques were applied to identify crack initiation and propagation and more importantly whether cracking behavior was comparable at different load levels for the equivalent and real mortar samples.
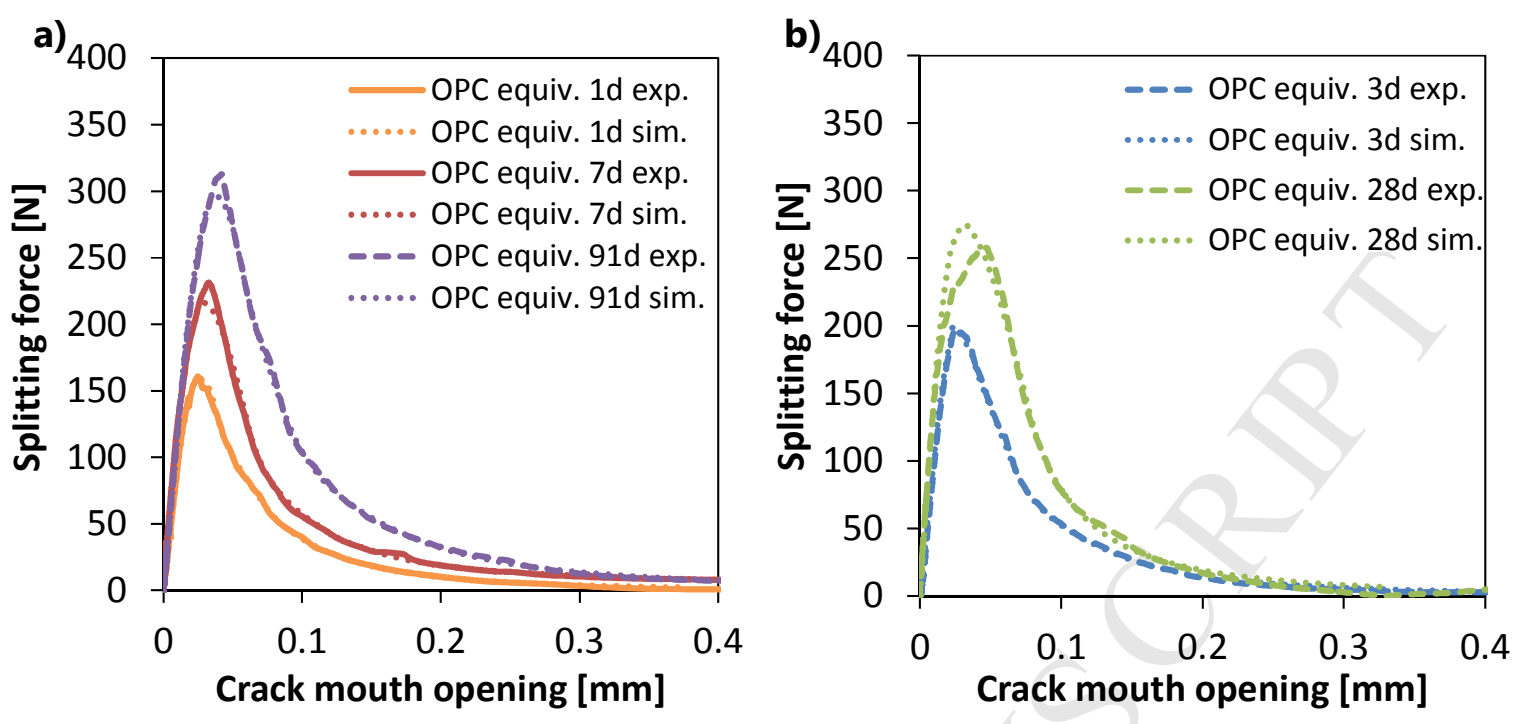
In Figure 12, the evolution of the crack initiation and propagation during CTT for two different hydration ages is shown by means of an example. The comparison of the real and equivalent mortar behavior at ages of $1 \mathrm{~d}$ and $3 \mathrm{~d}$ is shown in Figure 12a and Figure 12b, respectively. In Figure 12, the displacement interpolated at the facets overlay on top of the documented area is also shown. However, it should be noted that the facets overlay is here solely used to better visualize the crack initiation and propagation.

To directly compare the crack initiation and propagation in the real and equivalent mortars during testing, four different stages of the load-displacement curve are reported. For each hydration age, the first three stages are marked in the corresponding load-displacement curves. Stages 1 and 2 represent available strain fields right before and after cracking has occurred. During propagation (stage 3), one picture for the real and one for the equivalent mortars were selected at approximately similar loads. Finally, stage 4 was selected as the last strain field before the sample completely split. Stage 4 is not marked in the respective load-displacement curve, but it is shown in the respective pictures sequence.

The cracks are generally straight, starting at the tip of the notch and propagating to the opposite edge without signs of branching. This observation further reinforces the applicability of the applied inverse analysis and FEM approach to determine the fracture and the mechanical properties of the real and equivalent mortar systems. Besides the shape of the crack, it should be noted that in stage 3 a direct comparison of the real and equivalent mortar suggest a similar crack opening for the applied load.

Further, this analysis extends the validity of the equivalent approach. Indeed, besides the similarity of the materials properties investigated in this study and the previous one [7], the equivalent systems also show a similar cracking behavior.

In light of the excellent agreement of the material properties investigated in this paper between the real and equivalent mortars and the similarity of the crack patterns at comparable load levels, the equivalent system approach further confirms the results shown with regards to the material properties investigated in the previous sections as well as the evaluation and conclusions reported in [7]. This powerful technique can therefore be used to investigate several hydration-dependent properties such as drying shrinkage, creep/relaxation, early-age cracking, and transport properties at early age. Recently, the early-age ultimate drying shrinkage of cement-based mortars was investigated through the use of the equivalent systems [28]. 

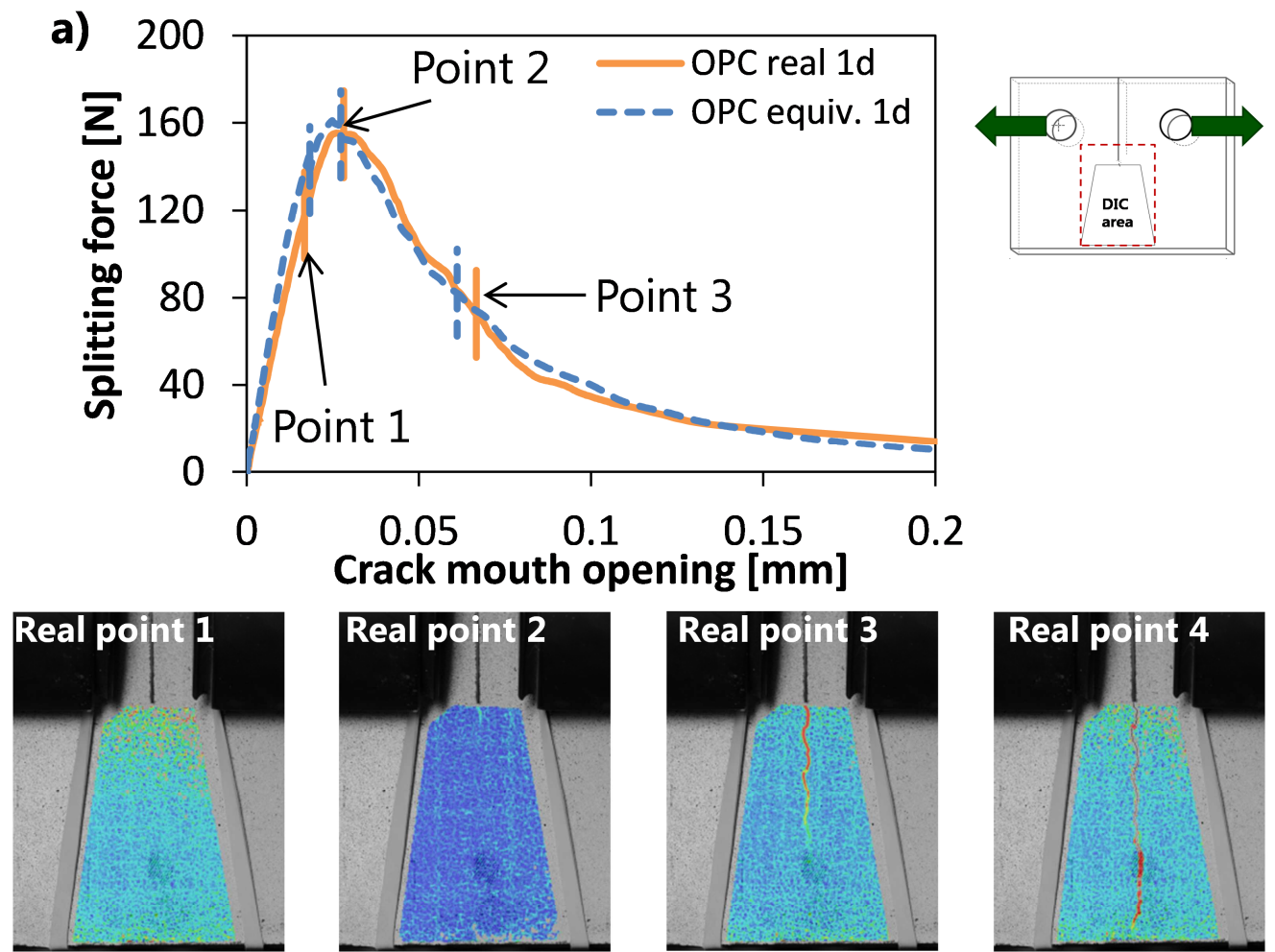

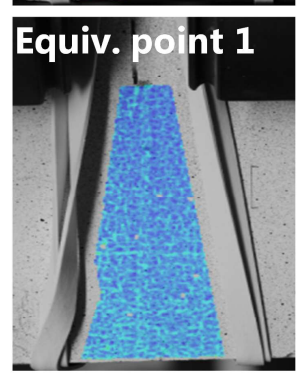

Before cracking initiation

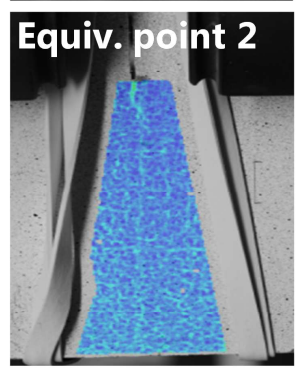

After cracking initiation

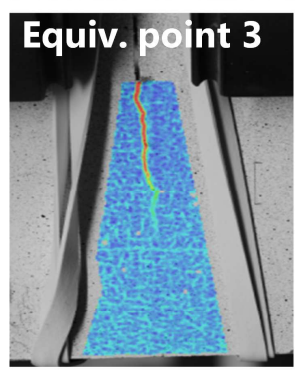

Cracking at $\sim 50 \%$ the peak load

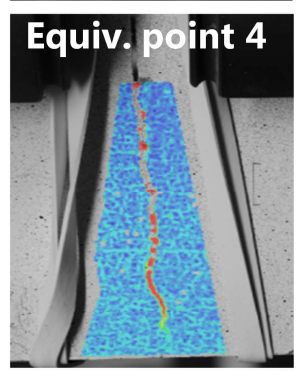

Cracking right before splitting 

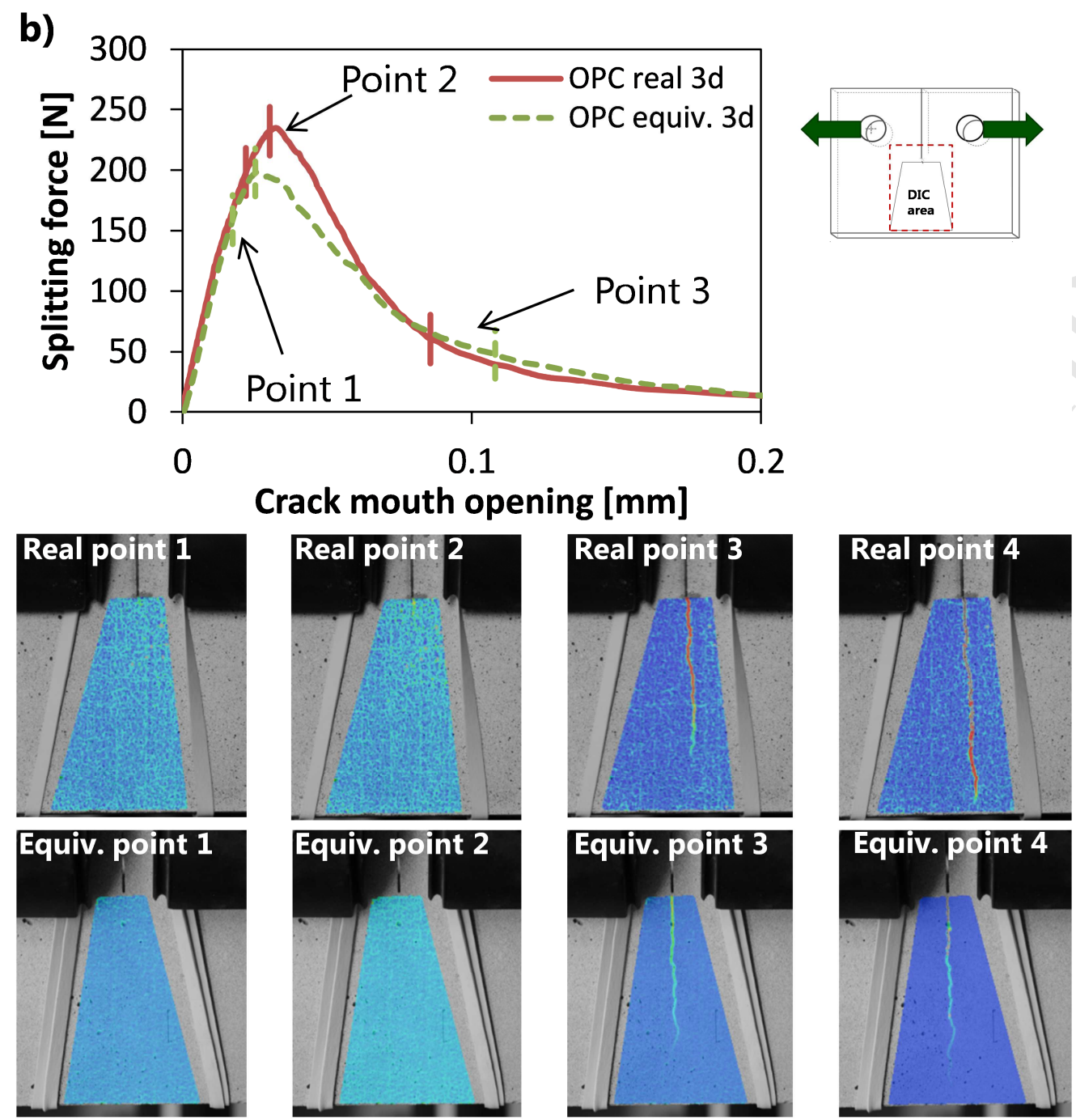

Before

After cracking initiation

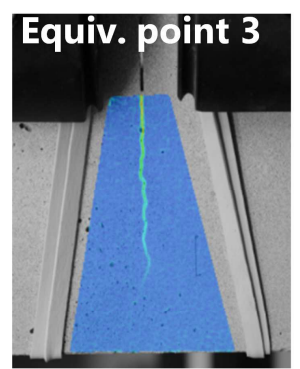

Cracking at 25\% the peak load

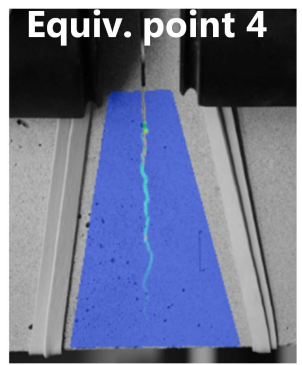

Cracking right before splitting 454 split.

455

456

457

458

Figure 12. Sequence of frames showing the crack patterns on the surface of the specimens at different loading levels. Comparison between real and the equivalent mortars at a) $1 \mathrm{~d}$ and b) $3 \mathrm{~d}$ of hydration. The Real point 4 and the Equiv. point 4 (not marked in the top images: Splitting force versus Crack mouth opening) represent the last strain field before the sample completely

\subsection{Early-age fracture properties as a function of moisture content}

In general, in real field conditions concrete is subjected to drying as soon as exposed to the environment (once the curing period is over). The investigation of the materials properties at 
early age such as the elastic modulus becomes of paramount importance. Thus, besides allowing for the simulation of different stages of the evolution of the microstructure with unchanging systems, the equivalent approach allows also to study the same system at different stages of drying in regard for example to elastic modulus, tensile strength, and fracture energy. In real cement based materials, it is possible to investigate the effect of moisture content only on mature samples, since the drying process takes several days to months to complete and rapid drying may lead to (micro)cracking and deterioration of the mechanical properties.

Equivalent mortar samples reproducing the equivalent ages of 1, 7, and $91 \mathrm{~d}$ with the geometry shown in Figure 1 were prepared. Three specimens repetition at each equivalent age were tested. Those ages were chosen as the microstructure and hence the material properties are quite different.

After 3 months curing, the samples were placed in an oven at $50{ }^{\circ} \mathrm{C}$ for about 1 month. It should be noted that due to the reduced thickness employed to measure the load-displacement curve, the drying of the samples was obtained in a reduced time (equilibrium was reached within approximately 3 weeks), while minimizing possible cracking due to occurrence of moisture gradients (self-restraint). The mass loss of the sample was monitored over time (every $48 \mathrm{~h}$ ) and equilibrium was assumed to be reached once the mass difference between two consecutive measurements was below $0.1 \%$. Further, the temperature of $50{ }^{\circ} \mathrm{C}$ was chosen to minimize possible microstructural damage such as crack formation due to differential shrinkage, and possible temperature-induced microstructural changes [29]. For example, ettringite starts to decompose above $60{ }^{\circ} \mathrm{C}[29,30]$.

Figure 13 (from a through c) shows the comparison between the elastic modulus, tensile strength, and fracture energy results for the equivalent systems in saturated and dried conditions. The error bars represent the standard deviation.

While the elastic modulus does not seem to be affected by the moisture content, the tensile strength appears to be dependent on the moisture content, which confirms the results of previous studies [31]. For each of the equivalent ages investigated, the tensile strength of the dried specimens is approximately two times higher. This is in accordance with the general strength reduction observed in cementitious material at higher moisture contents [32, 33]. Similar trends are observed for the fracture energy, which also increases for lower moisture contents; however, it should also be noted that the standard deviation associated with the results from the dried specimens is much higher. 
491 It should be noted that in real field exposures, especially at early age when the concrete is more

492

493

494

495

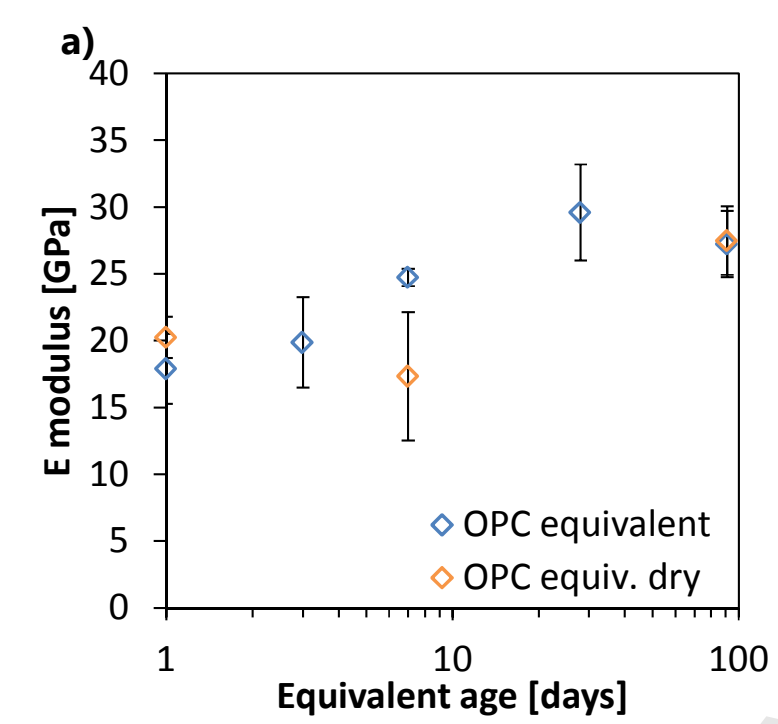

496

497

498

499

500

501

502

503 tensile strength of the skin concrete.

\section{Conclusions} susceptible to cracking, drying will induce on one hand the shrinkage and hence an increased cracking potential in restrained conditions, but on the other hand drying will also increase the
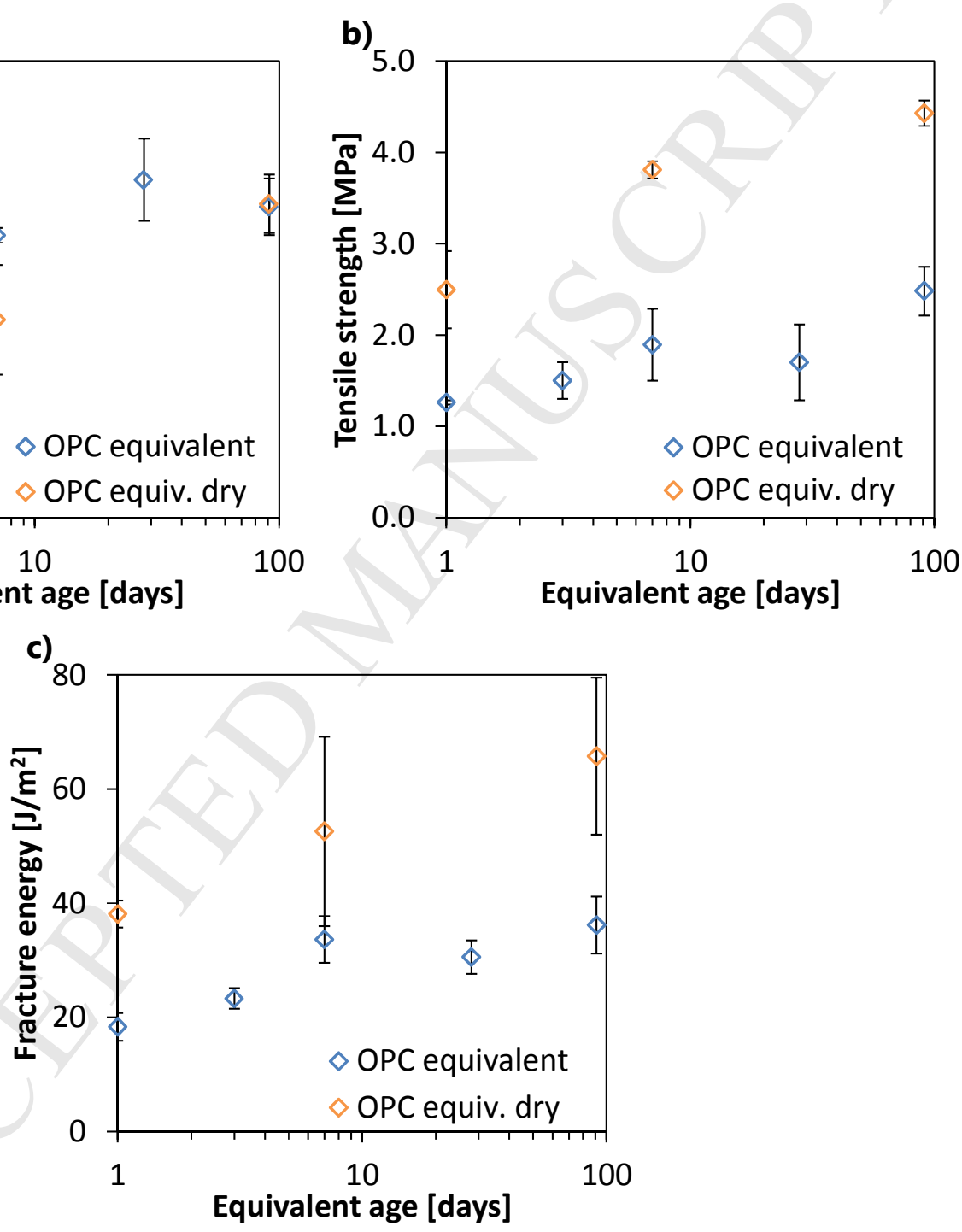

Figure 13. Comparison equivalent mortars in saturated and dry conditions a) elastic modulus b) tensile strength and c) fracture energy as a function of the equivalent age.

In this paper, the validation of the equivalent system technique applied to OPC mortars has been extended to the determination of fracture properties. The elastic modulus, tensile strength, and 
fracture energy, obtained by inverse analysis of the load-displacement curves for the real and equivalent mortar mixtures, were compared. The differences between the real and the equivalent mortars were statistically quantified by means of ANOVA. Further, the crack initiation and propagation in the real and equivalent mortars was monitored by means of DIC.

The experimentally-determined load-displacement curves obtained by means of the CTT for real and equivalent mortars showed excellent agreement.

The elastic modulus, tensile strength, and fracture energy results determined by inverse analysis based on the hinge model also supported the hypothesis of similarity between the real and equivalent mortars. The statistical analysis through ANOVA and MANOVA showed that no statistically significant difference (at significance level of 0.05 ) was observed for the material properties investigated.

To validate the accuracy of the results obtained by the inverse analysis, a FEM model simulating the sample tested in CTT was built. Excellent agreements between experimentally determined and computed load-displacement curves were found for all mortar systems.

Further, the elastic modulus results obtained by inverse analysis were compared to static and dynamic elastic moduli measured on companion specimens. Good agreements between results obtained by inverse analysis for both the real and equivalent mortars with the statically determined ones were obtained for most of the test specimens.

Finally, the DIC technique revealed that crack initiation and propagation evolved similarly in the two systems at similar load levels.

Experimental results suggest that the equivalent approach is a powerful method to investigate hydration-dependent and/or moisture-dependent properties. The use of the equivalent approach indeed allows investigations at early age that are otherwise difficult or impossible to perform because of the ongoing hydration while on the other hand moisture-dependent testing requires drying.

To this end, the effect of the moisture content on the elastic modulus, tensile strength, and fracture energy at early-age was investigated. The tensile strength at all ages appears to be the most sensitive to the presence of moisture, increasing systematically upon drying. Despite a less pronounced difference, also the fracture energy seems to increase as the moisture level decreases. On the other hand, the elastic modulus does not seem to be affected. 


\section{Acknowledgement}

The authors are grateful to the Nanocem consortium for funding this study (Core Project 13, Early-Age Shrinkage and Cracking of Cementitious Materials). The authors want also to thank Dr. Jan Skoček, Dr. Arnd Eberhardt and Dr. Mateusz Wyrzykowski for their insightful suggestions.

\section{References}

[1] Mehta PK. Reducing the environmental impact of concrete. Concrete international. 2001;23(10):61-6.

[2] Di Bella C, Villani C, Hausheer E, Weiss J. Chloride transport measurements for a plain and internally cured concrete mixture. ACI Special Publication. 2012;290.

[3] Holt E, Leivo M. Cracking risks associated with early age shrinkage. Cement and Concrete Composites. 2004;26(5):521-30.

[4] Springenschmid R. Prevention of thermal cracking in concrete at early ages: CRC Press; 1998.

[5] Østergaard L. Early-age fracture mechanics and cracking of concrete, PhD Thesis, Technical University of Denmark; 2003.

[6] De Schutter G. Finite element simulation of thermal cracking in massive hardening concrete elements using degree of hydration based material laws. Computers \& Structures. 2002;80(27):2035-42.

[7] Di Bella C, Wyrzykowski M, Griffa M, Termkhajornkit P, Chanvillard G, Stang H, et al. Application of microstructurally-designed mortars for studying early-age properties: Microstructure and mechanical properties. Cement and Concrete Research. 2015;78:234-44.

[8] Termkhajornkit P, Barbarulo R, Chanvillard G. Microstructurally-designed cement pastes: A mimic strategy to determine the relationships between microstructure and properties at any hydration degree. Cement and Concrete Research. 2015;71:66-77.

[9] Zhou FP. Some aspects of tensile fracture behaviour and structural response of cementitious materials. Report TVBM 1008. 1988.

[10] Østergaard L, Stang H, Olesen JF. Interpretation and inverse analysis of the wedge splitting test. Fracture Mechanics Beyond. 2000;2:593-600.

[11] Shah SP, Swartz SE, Ouyang C. Fracture mechanics of concrete: applications of fracture mechanics to concrete, rock and other quasi-brittle materials: John Wiley \& Sons; 1995. 
568

569

570

571

572

573

574

575

576

[12] Wittmann F, Roelfstra P, Mihashi H, Huang Y-Y, Zhang X-H, Nomura N. Influence of age of loading, water-cement ratio and rate of loading on fracture energy of concrete. Materials and structures. 1987;20(2):103-10.

[13] Skoček J, Stang H. Inverse analysis of the wedge-splitting test. Engineering Fracture Mechanics. 2008;75(10):3173-88.

[14] Pereira E, Fischer G, Barros JA. Characterization of cracking in strain hardening cementitious composites using the compact tension test. 8th RILEM International Symposium on Fibre Reinforced Concrete: challenges and opportunities; 2012.

[15] Chu T, Ranson W, Sutton M. Applications of digital-image-correlation techniques to experimental mechanics. Experimental mechanics. 1985;25(3):232-44.

[16] Oehlert GW. A first course in design and analysis of experiments. W H Freeman. 2010.

[17] NF-EN-196-1. Standard NF EN 196-1. Methods of testing cement. Determination of strength. 2005;22 March 2005.

[18] Ulfkjær JP, Krenk S, Brincker R. Analytical model for fictitious crack propagation in concrete beams. Journal of Engineering Mechanics. 1995;121(1):7-15.

[19] Olesen JF. Fictitious crack propagation in fiber-reinforced concrete beams. Journal of Engineering Mechanics. 2001;127(3):272-80.

[20] Pease BJ. Influence of concrete cracking on ingress and reinforcement corrosion. 2011.

[21] GOM. Aramis user manual - Software, Aramis v6.1 and higher. GOM Optical Measuring Techniques. 2009.

[22] Savic V, Hector Jr L, Fekete J. Digital image correlation study of plastic deformation and fracture in fully martensitic steels. Experimental Mechanics. 2010;50(1):99-110.

[23] Berfield T, Patel J, Shimmin R, Braun P, Lambros J, Sottos N. Micro-and nanoscale deformation measurement of surface and internal planes via digital image correlation. Experimental Mechanics. 2007;47(1):51-62.

[24] Team RC. R: A language and environment for statistical computing. R Foundation for Statistical Computing, Vienna, Austria, 2012. ISBN 3-900051-07-0; 2014.

[25] Karihaloo B, Huang X. Tensile response of quasi-brittle materials. pure and applied geophysics. 1991;137(4):461-87.

[26] Petersson P. Fracture energy of concrete: practical performance and experimental results. Cement and Concrete Research. 1980;10(1):91-101. 
599 [27] Di Bella C, Griffa M, Ulrich T, Lura P. Early-age elastic properties of mortars as a function 600 of decreasing moisture content. Cement and Concrete Research. 2016;89:87-96.

601 [28] Di Bella C, Wyrzykowski M, Lura P. Evaluation of the ultimate drying shrinkage of cement602 based mortars with poroelastic models. Materials and Structures. 2017;50(1):1-13.

603 [29] Gallé C. Effect of drying on cement-based materials pore structure as identified by mercury 604 intrusion porosimetry: a comparative study between oven-, vacuum-, and freeze-drying. Cement 605 and Concrete Research. 2001;31(10):1467-77.

606 [30] Murat M. Stabilité thermique des aluminates de calcium hydrates et phases apparentes. 607 Caractérisation par les méthodes thermoanalytiques. Aluminates de calcium, M Murat, A 608 Bachiorrini, B Guilhotet. 1982:59-84.

609 [31] Rossi P. Influence of cracking in the presence of free water on the mechanical behaviour of 610 concrete. Magazine of concrete research. 1991;43(154):53-7.

611 [32] Yurtdas I, Peng H, Burlion N, Skoczylas F. Influences of water by cement ratio on 612 mechanical properties of mortars submitted to drying. Cement and Concrete Research. $613 \quad 2006 ; 36(7): 1286-93$.

614 [33] Li G. The effect of moisture content on the tensile strength properties of concrete, Master 615 Thesis University of Florida; 2004. 